\title{
A Seven-Year Storage Report of Good Manufacturing Practice-Grade Naked Plasmid DNA: Stability, Topology, and In Vitro/In Vivo Functional Analysis
}

\author{
Wolfgang Walther, ${ }^{1}$ Marco Schmeer, ${ }^{2}$ Dennis Kobelt, ${ }^{3}$ Ruth Baier, ${ }^{2}$ Alexander Harder, ${ }^{4}$ \\ Volker Walhorn, ${ }^{4}$ Dario Anselmetti, ${ }^{4}$ Jutta Aumann, ${ }^{1}$ Iduna Fichtner, ${ }^{3}$ and Martin Schleef ${ }^{2}$
}

\begin{abstract}
The great interest for naked plasmid DNA in gene therapy studies is reflected by the fact that it is currently used in $18 \%$ of all gene therapy trials. Therefore, validation of topology and functionality of DNA resulting from its long-term stability is an essential requirement for safe and effective gene transfer. To this aim, we analyzed the stability of good manufacturing practice-grade $\mathrm{pCMV} \beta$ reporter plasmid DNA by capillary gel electrophoresis, agarose gel electrophoresis, and atomic force microscopy. The plasmid DNA was produced for a clinical gene transfer study started in 2005 and was stored for meanwhile 7 years under continuously monitored conditions at $-20^{\circ} \mathrm{C}$. The stability of plasmid DNA was monitored by LacZ transgene expression functional assays performed in vitro and in vivo on the 7-year-old plasmid DNA samples compared with plasmid batches newly produced in similar experimental conditions and quality standards. The analyses revealed that during the overall storage time and conditions, the proportion of open circular and supercoiled or covalently closed circular forms is conserved without linearization or degradation of the plasmid. The in vitro transfection and the in vivo jetinjection of DNA showed unaltered functionality of the long-stored plasmid. In summary, the 7-year-old and the newly produced plasmid samples showed similar topology and expression performance. Therefore, our stable storage conditions are effective to preserve the integrity of the DNA to be used in clinical studies. This is an important prerequisite for the long-term performance of gene transfer materials used in trials of long duration as well as of the reference material used in standardization procedures and assays.
\end{abstract}

\section{Introduction}

$\mathbf{N}$ ONVIRAL GENE THERAPY VECTORS are of great importance, and they are used in $18 \%$ of the total number of clinical trials (Edelstein et al., 2007; Schleef et al., 2010; Ginn, 2013). This is because of their intrinsic biosafety characteristics and many technological improvements, which made nonviral vectors a promising alternative over viral vectors in gene therapy. The attractiveness of nonviral vectors is based on their favorable characteristics, such as low toxicity and immunogenicity, in association with continuously improving expression efficiencies (Gill et al., 2009; Tolmachov, 2009; Haase et al., 2010). For the use of plasmid DNA in clinical applications, there are two main requirements: the high product purity and product stability for the final formulation. Both are achieved by proper manufacturing and storage conditions. The technology of large-scale production of plasmid DNA required for clinical applications has been significantly improved since more than a decade (Schleef and Blaesen, 2009; Schleef et al., 2010). This includes also the progress made in plasmid purification, which is closely associated with improvements in long-term DNA stability (Walther et al., 2003; Schleef and Bleasen, 2009). This progress is paralleled with the development of physical transfer technologies of naked DNA, such as electroporation, particle bombardment, jet-injection, and ultrasound (sonoporation), which are often used to improve transfer efficiencies (AlDosari and Gao, 2009). With respect to the clinical use of plasmid

\footnotetext{
${ }^{1}$ Experimental and Clinical Research Center, Charité University Medicine Berlin, Max-Delbrück-Center for Molecular Medicine, 13125 Berlin, Germany.

${ }^{2}$ PlasmidFactory GmbH \& Co. KG, 33607 Bielefeld, Germany.

${ }^{3}$ Max-Delbrück-Center for Molecular Medicine, 13125 Berlin, Germany.

${ }^{4}$ Experimental Biophysics \& Applied Nanoscience, Faculty of Physics, and Bielefeld Institute of Biophysics and Nanoscience, Bielefeld University, 33615 Bielefeld, Germany.
} 
DNA, the good manufacturing practice (GMP) guidelines oblige high-quality standards not only concerning the production process, but also during storage of the DNA at controlled conditions. The appropriate storage of DNA batches is essential to maintain constant and reliable quality, stability, and functionality of the DNA. Ideally, the storage conditions should preserve the GMP-grade DNA at those quality parameters, which were achieved at the time of the actual production. For DNA vaccination studies, for instance, long-term stability of plasmid DNA is a decisive factor for reproducible clinical results (Lara and Ramirez, 2012). This is the essential demand for the development of plasmid DNA-based pharmaceuticals, which have to be stored and shipped under controlled and documented conditions for long time, and the DNA stability and functionality must be preserved during storage (Zheng et al., 2011). In this context, only a few studies exist, which analyze long-term stability parameters of unmodified, naked plasmid DNA stored for more than 12 months. Such studies are of importance especially for plasmid DNA in solution, since Voss et al. (2005) showed that its lyophilization may negatively influence plasmid topologies. In recent studies (PlasmidFactory, unpublished) the possibility to lyophilize and resuspend plasmid DNA was demonstrated without damaging the supercoiled covalently closed circular (ccc) form. However, the ability to completely resuspend the DNA is mandatory and is highly dependent on DNA purity. In an earlier study, we have shown that storage temperature rather than the duration of storage is important to preserve plasmid topology (Walther et al., 2003; Voss, 2007).

In this article, we extended our study in analyzing the stability and functionality of the $\mathrm{pCMV} \beta$ reporter plasmid DNA produced in 2005 for a phase I clinical study (DeReGe62) (Walther et al., 2008) and stored at $20^{\circ} \mathrm{C}$ or lower, by capillary and agarose gel electrophoresis (AGE), atomic force microscopy (AFM), and reporter gene expression analyses in vitro and in vivo compared with a fresh batch produced in a comparable production process shortly before these experiments have been performed.

\section{Materials and Methods}

\section{Plasmid DNA}

The Escherichia coli $\beta$-galactosidase (LacZ)-expressing plasmid $\mathrm{pCMV} \beta$ (7,164 bp; Clontech) was produced and tested in 2005 in collaboration with PlasmidFactory according to the GMP guidelines for a phase I clinical gene transfer trial (DeReGe 62) (Walther et al., 2008). In brief, transformed E. coli were cultivated under controlled conditions by fermentation. After alkaline lysis of harvested bacteria, plasmids were purified by a anion exchange chromatography procedure. The resulting preparations were free of adventitious bacteria and endotoxin, meeting the specifications summarized in Table 1. The plasmid concentration was adjusted to $1 \mu \mathrm{g} / \mu \mathrm{l}$ in $0.9 \%$ sodium chloride. At the time of production, plasmid identity was confirmed by DNA sequencing, and plasmid topology was analyzed by capillary gel electrophoresis (CGE). The unused, unopened sterile batches of this plasmid DNA were stored for 7 years under controlled conditions at less than or equal to $-20^{\circ} \mathrm{C}$ at PlasmidFactory's GMP storage facility. For comparative analyses, the same plasmid was recently produced by PlasmidFactory, and quality standards were applied as state of the art for the GMP production 7 years ago in order to achieve comparability of the resulting DNA, meeting the same specifications as defined for the GMP batch.

\section{CGE analysis of plasmid topology}

The CGE analyses of the different $\mathrm{pCMV} \beta$ plasmid batches were performed to evaluate long-term stability of plasmid DNA topology. The plasmid pUK21 (PlasmidFactory) was used as a reference standard. CGE analyses were performed using a Beckman P/ACE MDQ instrument equipped with an laser induced fluorescence (LIF) detector $(488 / 520 \mathrm{~nm})$ as described (Schmidt, 1999; Walther, 2003). Briefly, coated capillaries (DB-17; J\&W Scientific) with an effective length of $30 \mathrm{~cm}$ to the detector window, an inner diameter of $100 \mu \mathrm{m}$, and a coating thickness of $0.1 \mu \mathrm{m}$ were used. The capillary was flushed with a buffer solution, and just before analysis, the intercalating dye YOYO (Molecular Probes) was added. After prestaining with YOYO, the plasmid samples were introduced hydrodynamically, and electrophoresis was carried out at $100 \mathrm{~V} / \mathrm{cm}$ and $30^{\circ} \mathrm{C}$. Peak surfaces were measured to quantify the amount of each DNA forms, and data are presented in Table 2.

\section{AGE analysis of plasmid topology}

The various isoforms in a plasmid preparation were made visible by AGE by using $250 \mathrm{ng}$ plasmid DNA

Table 1. Specifications for the Good Manufacturing Practice Batch of 2005 as Applied for the Newly-Produced Plasmid DNA Batch

\begin{tabular}{lll}
\hline Test & \multicolumn{1}{c}{ Specification } & \multicolumn{1}{c}{ Analytical method } \\
\hline Appearance & Clear, no visible particles & Visual inspection \\
DNA concentration & $1 \mathrm{mg} / \mathrm{ml}( \pm 5 \%)$ & UV absorption $260 \mathrm{~nm}$ \\
DNA purity & Peak at $258 \mathrm{~nm}$ & UV scan $(220-320 \mathrm{~nm})$ \\
Plasmid identity & Restriction pattern & Restriction digestion and AGE \\
& conforms with DNA sequence. & \\
RNA & Not visible & Visual inspection after AGE \\
Bacterial chromosomal DNA & Not visible & Visual inspection after AGE \\
DNA homogeneity (total ccc content) & $\geq 90 \% \mathrm{ccc}$ & Capillary gel electrophoresis \\
Endotoxin (LPS) & $\leq 100 \mathrm{E} . \mathrm{U} . / \mathrm{mg}$ DNA & Quantitative Limulus amebocyte lysate assay \\
Protein & $<10 \mu \mathrm{g} / \mathrm{mg}$ & Bicinchoninic acid assay \\
Microorganisms & $<1 \mathrm{CFU} / \mathrm{ml}$ & Bioburden test
\end{tabular}

AGE, agarose gel electrophoresis; ccc, covalently closed circular; LPS, lipopolysaccharide endotoxin. 
Table 2. Quality Control Analysis by Capillary Gel Electrophoresis of 7-Year-Old Good MANUfacturing Practice Plasmid DNA Compared with Newly Prepared Plasmid DNA

\begin{tabular}{lccc}
\hline & $\begin{array}{c}\text { GMP } \\
\text { plasmid } \\
\text { DNA }\left(2005^{\mathrm{a}}\right)\end{array}$ & $\begin{array}{c}\text { 7-year GMP } \\
\text { plasmid } \\
\text { DNA }\end{array}$ & $\begin{array}{c}\text { New } \\
\text { plasmid } \\
\text { DNA }\end{array}$ \\
\hline $\begin{array}{lccc}\text { Topologies } \\
\text { Percent cc monomer }\end{array}$ & $97.3^{\mathrm{a}}$ & 91.9 & 91.9 \\
Percent cc dimer & & 5.0 & 6.3 \\
\hline
\end{tabular}

The percentages are expressed as mean of two separate capillary gel electrophoresis runs.

a The data originate from the analysis performed in 2005, which at this time did not distinguish between a ccc monomer and a ccc dimer. GMP, Good Manufacturing Practice; oc, open circular.

electrophoresed through $0.8 \%$ agarose gels at $10 \mathrm{~V} / \mathrm{cm}$ and subsequently stained with $500 \mu \mathrm{g} / \mathrm{ml}$ ethidium bromide. The fluorescent bands were made visible on a UV transilluminator at $312 \mathrm{~nm}$. Although the electrophoretic mobility of different plasmid DNA structures may change according to the electrophoresis conditions, in general, the supercoiled ccc monomer forms move most rapidly, followed by the open circular (oc) monomer forms and $\mathrm{ccc}$ dimer forms. However, a clear distinction of the ccc dimers and oc monomers is generally recognizable only in smaller plasmids.

\section{Endotoxin content (Limulus amebocyte lysate)}

The gram-negative bacterial endotoxin content in a plasmid DNA solution was determined by the kinetic chromogenic test Kinetic-QCL Kinetic Chromogenic Assay (Lonza; Prod. no. 50-650U) according to the manufacturer's protocol.

\section{Protein content (bicinchoninic acid assay)}

The quantification of the total protein content in a plasmid DNA solution is determined by the chromogenic test BCA ${ }^{\mathrm{TM}}$ Protein Assay Kit (Pierce; Prod. no. 23227) according to the manufacturer's protocol.

\section{AFM microscopy}

The atomic force microscope is a versatile tool to map and measure biological structures with high resolution and accuracy at the nanometer scale (Anselmetti et al., 1994). Our plasmid DNA molecules were visualized by AFM by using a commercial instrument (Multimode AFM; Bruker) in AFM tapping operation mode conditions. Briefly, the basic setup consists of a microfabricated cantilever force sensor with an integrated tip and a piezo scan tube on which the sample is placed. By scanning the cantilever tip over the sample surface, the topography can be visualized. Our DNA samples were immobilized on a mica surface that has been functionalized with aminopropyltriethoxysilane by gas-phase silanization, rendering a smooth and homogeneously positively charged surface (Lyubchenko et al., 1993). The molecules were allowed to adsorb in the buffer solution for $10 \mathrm{~min}$. Then, the surface was rinsed with ultrapure water and dried in a clean jet of nitrogen gas.

\section{Cells}

The human SW480 cell line (colon carcinoma) was used for functional analysis of the plasmid DNA in $\beta$-galactosidase (LacZ) reporter gene expression assays. Cells were grown in RPMI medium (Invitrogen), supplemented with 10\% fetal calf serum (Biochrom) at $37^{\circ} \mathrm{C}$ in $5 \% \mathrm{CO}_{2}$ incubator.

\section{Transfection}

About $4 \times 10^{5}$ cells were seeded into 6-well plates, and the medium was supplemented with $2 \mu \mathrm{g} /$ well of the $\mathrm{pCMV} \beta$ plasmid DNA using Fugene HD as recommended by the manufacturer (Roche Diagnostics).

\section{In vivo jet-injection}

Female NMRI nu/nu mice xeno-transplanted with human colon tumors (EPO GmbH) (Walther et al., 2001; Fichtner et al., 2004) were used for nonviral in vivo jet-injection gene transfer of the $\mathrm{pCMV} \beta$ plasmids. The mice were anesthetized and received five jet-injections using the Jet-Injector (EMS Medical $\mathrm{GmbH}$ ) at a pressure of 3.0 bar through the skin directly into the tumor (Walther et al., 2001). In each jetinjection, $10 \mu \mathrm{l}$ of the plasmid solution containing $1 \mathrm{mg} / \mathrm{ml}$ of naked plasmid DNA was delivered. About $48 \mathrm{hr}$ after jet-injection, animals were sacrificed, and tumors were harvested and analyzed. The control animals received phosphate buffered saline (PBS) jet-injections. The animal experiments were performed according to the German Animal Protection Law and with approval from the local authorities (LaGeSo).

\section{$X$-Gal staining}

For cellular detection of LacZ expression in SW480 cells, transfected cells were fixed in $2 \%$ paraformaldehyde for $10 \mathrm{~min}$ at $4^{\circ} \mathrm{C}$, washed, and incubated with $3 \mathrm{ml} \mathrm{X}$-Gal mix (1 mg/ml 5-bromo-4-chloro-3-indolyl- $\beta$-D-galactoside [X-Gal], $1 \mathrm{mM} \mathrm{MgCl} 2,3 \mathrm{mM} \mathrm{K}{ }_{3} \mathrm{Fe}[\mathrm{CN}]_{6}$, and $3 \mathrm{mM} \mathrm{K}{ }_{4} \mathrm{Fe}[\mathrm{CN}]_{6}$ ) for $24 \mathrm{hr}$ at $37^{\circ} \mathrm{C}$ in 6-well plates to allow blue staining. Cells were washed with PBS and observed in a light microscope (Zeiss), and microphotographs were taken.

For the detection of LacZ expression in vivo, animals were euthanized $48 \mathrm{hr}$ after jet-injection, and tumors were harvested for preparation of cryosections. The cryosections $(7 \mu \mathrm{m})$ were fixed in $2 \%$ paraformaldehyde for $10 \mathrm{~min}$ at $4^{\circ} \mathrm{C}$ and rinsed twice with ice-cold PBS. The slides were then placed in quadriPERM plus chambers (Heraeus Instruments) and covered with $3 \mathrm{ml} \mathrm{X-Gal} \mathrm{mix} \mathrm{for} \beta$-galactosidase detection. The cryosections were incubated for at least $24 \mathrm{hr}$ at $37^{\circ} \mathrm{C}$ and then covered in Faramount aqueous mounting medium (Dako) for observation in a light microscope.

\section{LacZ enzyme-linked immunosorbent assay}

For quantification of LacZ expression, a LacZ enzymelinked immunosorbent assay (ELISA) was performed using lysates from transfected SW480 cells. For the preparation of cell lysates, cells were trypsinized and centrifuged, and resulting cell pellets were incubated with a lysis buffer (Roche Diagnostics) for $20 \mathrm{~min}$ on ice and centrifuged at 12,000 rpm. The clear supernatants were then subjected to the LacZ ELISA (Roche Diagnostics), which was performed according 

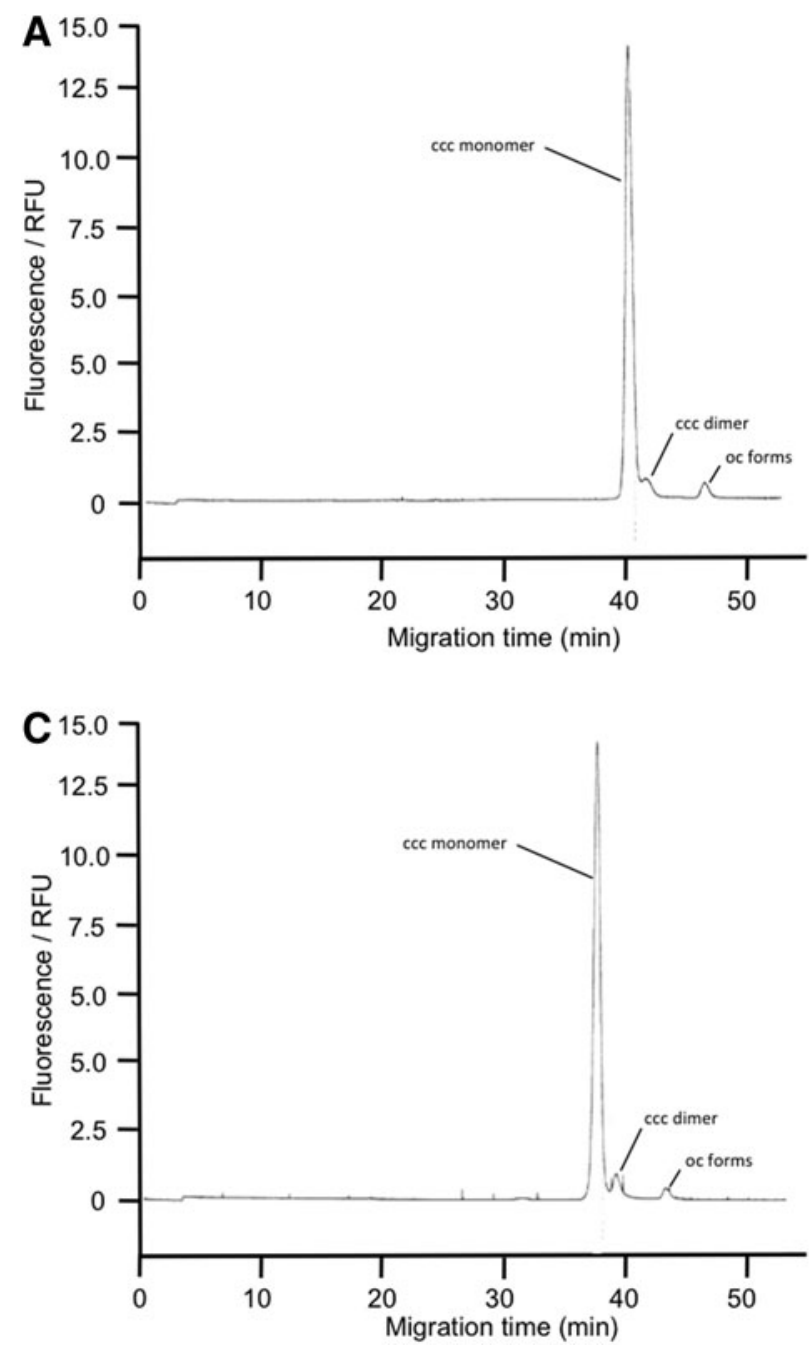

to the manufacturer's instructions. The kit provides its own standard reagent to generate reproducible standard curves. The ELISA selectively detects only the bacterial protein, but not endogenous $\beta$-galactosidase, with high sensitivity of $>30 \mathrm{pg} / \mathrm{ml}$. For LacZ ELISA from tumor cryosections, serial $7 \mu \mathrm{m}$ sections were incubated in the lysis buffer (Roche Diagnostics), centrifuged at $12,000 \mathrm{rpm}$, and subjected to the ELISA. For each ELISA, standard curves were generated. The absorbance was measured at $405 \mathrm{~nm}$ in a microplate reader (Tecan). The respective $\beta$-galactosidase values were calculated using EasySoftG20/Easy-Fit software (Tecan) and normalized to the protein concentration of the corresponding lysate, which was determined by the Coomassie Plus Protein Assay Reagent (Pierce). The standard curve was obtained with serial dilutions of bovine serum albumin $(1.25,2.5,5,10$, $12.5,25$, and $50 \mathrm{mg} / \mathrm{ml})$. The absorbance was measured at $595 \mathrm{~nm}$ in a microplate reader (Tecan).

\section{Results and Discussion}

\section{Analyses of plasmid DNA topologies by CGE and AGE}

In DNA-based pharmaceuticals, the stability of DNA and the maintenance of its functionality are essential biosafety requirements, especially for clinical applications. Therefore,
B

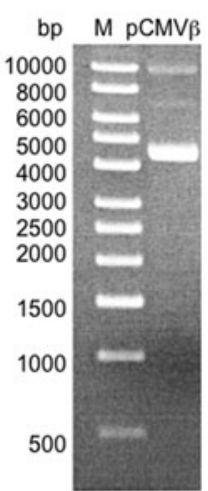

FIG. 1. Electropherograms of capillary gel electrophoresis analysis $(\mathbf{A}, \mathbf{C})$ and agarose gel electrophoresis (B, D) of the 7-year-old pCMV $\beta$ plasmid DNA $(\mathbf{A}, \mathbf{B})$ and of the newly produced plasmid (C, D). M, $1 \mathrm{kbp}$ DNA ladder; $\mathrm{pCMV} \beta$, plasmid DNA.
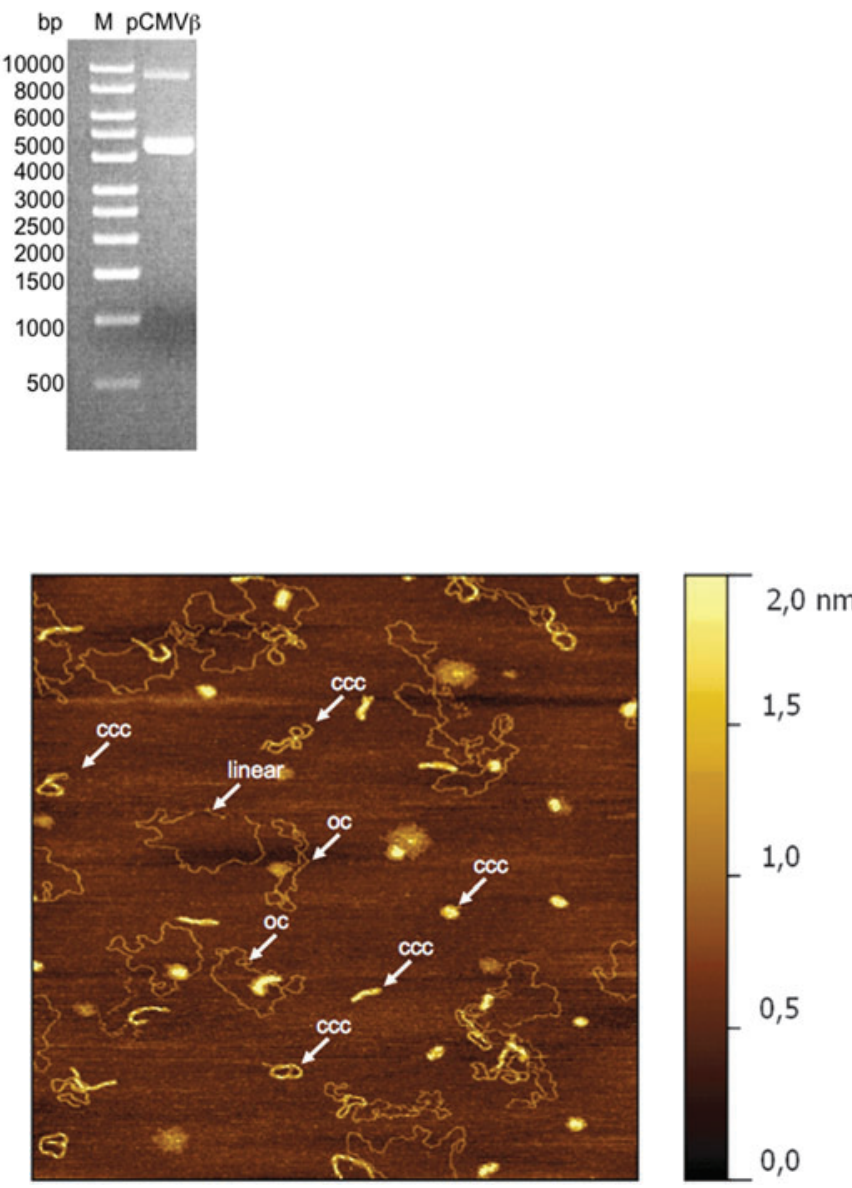

FIG. 2. AFM image of the 7-year-stored plasmid DNA. The AFM image shows ccc plasmid DNA of different degrees of condensation and oc forms (without linear forms, chromosomal DNA aggregates, or other contaminants). The figure shows an AFM image with an edge size of $3 \mu \mathrm{m}$. The altitude of the DNA above the surface (in $\mathrm{nm}$ ) is shown by different colors as indicated on the bar on the right-hand side of the AFM image. AFM, atomic force microscopy; ccc, covalently closed circular; oc, open circular. Color images available online at www.liebertpub.com/humc 
long-term storage of naked DNA, for instance, should be done under controlled conditions in association with quality controls of this DNA. In this study we analyzed the plasmid DNA that was produced in 2005 in GMP conditions to be used in a gene transfer clinical trial (Walther et al., 2008). We compared the topology of this 7-year-old plasmid DNA with that of newly produced DNA batches of the same plasmid. Since DNA topology is easily and reliably detectable by CGE, this method was used for the quantification of the eventual topological variations (ccc vs. non-ccc) of the plasmid DNAs and the assessment of DNA quality (Schmidt et al., 1999). CGE analysis defines plasmid isoforms by respective peak migration, and area as area/migration time ratio. Therefore, migration order in CGE analyses starts with ccc monomer, ccc dimer, and possible linear forms, followed by oc forms (monomer, dimer). Since the linearity between plasmid DNA concentration and the peak area has been demonstrated in previous studies, reliable quantitation of the plasmid topologies is possible (Voss et al., 2003; Schleef and Schmidt, 2004). Figure 1A and C shows the topology of the 7year-stored plasmid DNA compared with the newly produced one. Both CGE electropherograms reveal identical profiles of the specific peaks of ccc monomer, ccc dimer, and oc monomer, indicating thus that no degradation of the plasmid DNA occurred. The values obtained from the peak quantifications shown in Table 2 indicate identical percentages for the ccc monomer $(91.9 \%$ both) and only minor differences in the ccc dimer ( $5 \%$ vs. $6.3 \%$ ) and the oc monomer $(1.8 \%$ vs. $3.1 \%)$. At the time of plasmid production in 2005 , the CGE analysis revealed $96 \%$ for the ccc monomer,
FIG. 3. Functional in vitro and in vivo tests of the 7-year-stored and of the newly produced $\mathrm{pCMV} \beta$ plasmid. The in vitro LacZ expression is quantified in the ELISA (A) and visualized in vitro by $\mathrm{X}$-gal staining of transfected human colon carcinoma SW480 cells, and empty vector-transfected cells served as negative control for the $\mathrm{X}$-gal staining (B). (C) Quantification of the in vivo LacZ expression after jet-injection gene transfer with 7-year-stored and newly prepared plasmids. (D) In vivo LacZ expression, indicated as blue staining, in the tumor tissues after intratumoral jet-injection gene transfer with 7-year-stored and newly prepared plasmids. Animals jet-injected with phosphate buffered saline served as negative control for $\mathrm{X}$-gal staining. Color images available online at www.liebertpub.com/humc

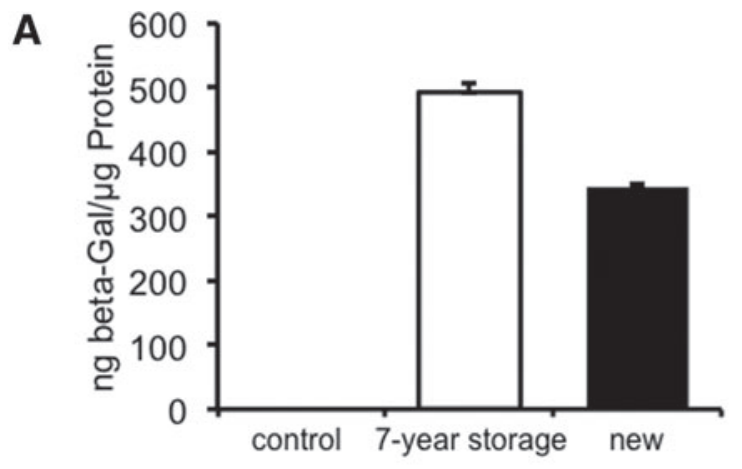

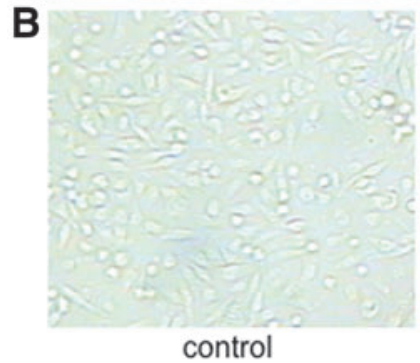

control
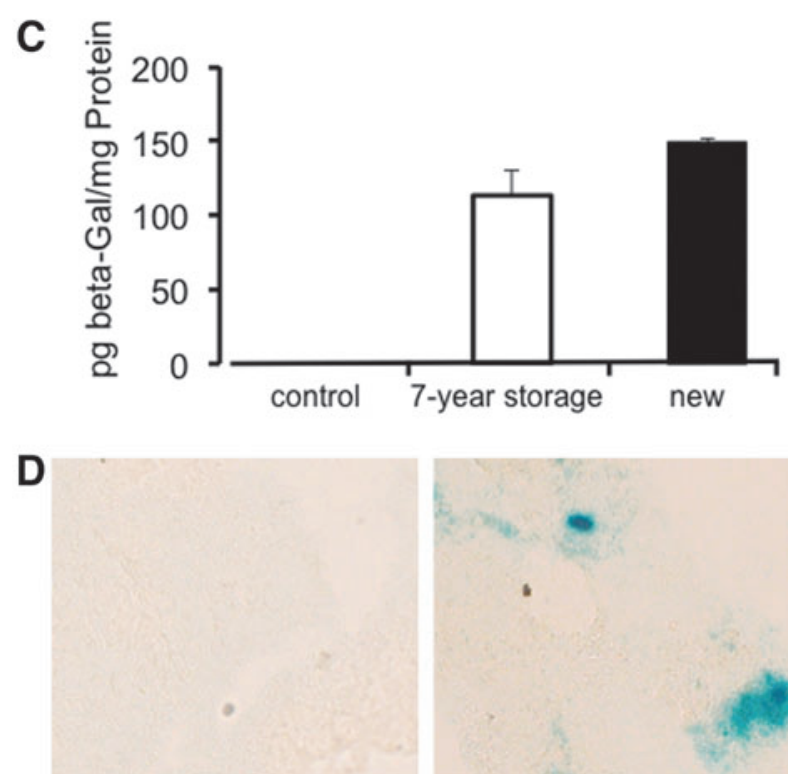

control

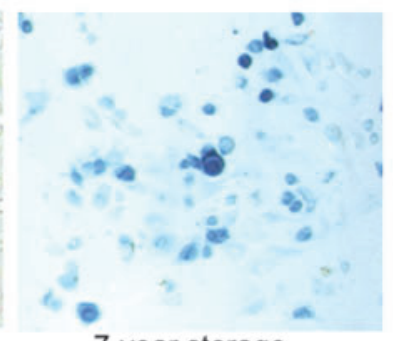

7-year storage

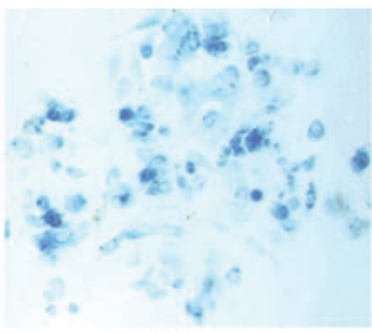

new

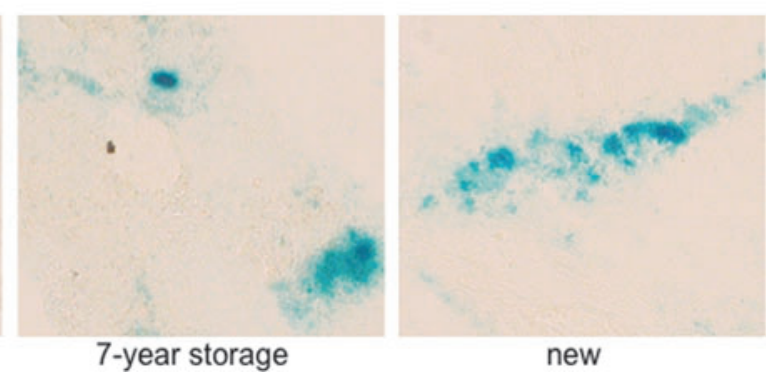


reflecting only a minor reduction by $4.1 \%$ during the 7 -year storage. More importantly, for both plasmid DNAs no linear forms were detected. The AGE supports the CGE data, particularly for possible degradation-related topologies of the plasmid DNAs, which were not detectable for both plasmids (Fig. 1B and D). These data indicate that even longterm storage of naked plasmid DNA at controlled conditions of $-20^{\circ} \mathrm{C}$ preserves the plasmid topology as long as for 7 years and prevents the plasmid from degradation. This is of primary importance when plasmid DNA is used for gene therapy studies because it has been shown that ccc forms of plasmid DNA are required for effective gene transfer compared with oc or linearized forms (Remaut et al., 2006; Tolmachov, 2009; Escoffre et al., 2012).

\section{AFM analysis}

The AFM is a valuable approach to analyze the plasmid DNA structures and topologies at the molecular resolution (Kim et al., 2011). In Fig. 2 the AFM top-view topography image shows in detail the 7-year storage $\mathrm{pCMV} \beta$ plasmid DNA in densely compacted ccc form. The ccc form can be easily distinguished from open circular (oc) and linear forms. The different superhelicity and coiling levels of the plasmids result in different sizes of the condensed ccc plasmids up to those being relaxed. Some molecules can be observed showing nicked or linear forms. AFM visualizes also the absence of contaminating material, such as solid particles or aggregates of chromosomal DNA fragments, which are difficult to resolve and are potentially influencing the transfection efficacy. Furthermore, the absence of bacterial chromosomal DNA, nicked plasmids, and of non-DNA material demonstrates that $0.2 \mu \mathrm{m}$ filtration, which is done for pharmaceutical-grade plasmid DNA, is an efficient procedure to obtain $\mathrm{pCMV} \beta$ plasmid DNA. This is indeed a valuable purification method for plasmid DNA preparations, especially if they contain significant amounts of bacterial chromosomal DNA resulting in aggregates of plasmid DNA and large chromosomal DNA fragments.

\section{Functional analyses of plasmid DNAs in vitro and in vivo}

Besides preservation of DNA topology during long-term storage, correct function regarding proper transgene expression is essential. Functionality of the 7-year plasmid and of the newly produced plasmid was tested in vitro and in vivo. The in vitro gene transfer with the $\mathrm{pCMV} \beta$ plasmids was performed in SW480 human colon carcinoma cells. The expression of the $\beta$-galactosidase reporter gene ( $\mathrm{LaCZ}$ ) was quantified in a LacZ-specific ELISA assay and evaluated in cytochemical X-gal staining. The ELISA shows that, even after long-term storage, Lac Z expression is not declined compared with the newly produced plasmid (492 ng LacZ/ $\mathrm{mg}$ protein vs. $345 \mathrm{ng} \mathrm{LacZ} / \mathrm{mg}$ protein; Fig $3 \mathrm{~A})$. This is further supported by the X-gal staining of transfected SW480 cells, showing similar transfection rates achieved with the 7year plasmid versus newly produced DNA (Fig. 3B). The plasmid function was also tested in vivo using the nonviral jet-injection gene transfer to apply the naked plasmid DNAs intratumorally into subcutaneous xenotransplants of human colon carcinoma (Walther, 2001). The LacZ expression was detected qualitatively by histochemical X-gal staining in the tumor cryosections. As shown, both plasmids exhibit effective LacZ expression in the tumors as blue-stained areas, which is independent from their storage time (Fig. 3C,D). The PBS control animals, however, show no staining for LacZ expression, indicating specificity of the X-gal staining. These in vitro and, more importantly, in vivo expression data clearly demonstrate that even very long but controlled stable storage conditions preserve the topology of naked plasmid DNA and ensure effective and reproducible transgene expression. The importance of stable storage conditions was earlier shown for plasmid DNA stored at $-80^{\circ} \mathrm{C}$ for 13 months (Walther, 2003). However, our current study significantly extends the earlier report, demonstrating that, after 7-year storage at $-20^{\circ} \mathrm{C}$, plasmid DNA topology and its functionality for gene therapy applications are preserved at a very high degree.

\section{Conclusions}

This study demonstrates that GMP-grade plasmid DNA can be stored for very long time preserving a very high degree of plasmid DNA topology (>90\%) and biological activity in terms of transgene expression. The CGE and AFM analyses revealed that storage of GMP-grade plasmid DNA in a solution at thoroughly controlled conditions $\left(-20^{\circ} \mathrm{C}\right)$ prevents degradation and preserves the applicability of plasmid DNA as a pharmaceutical. In vitro and in vivo testing of the 7-year-stored $\mathrm{pCMV} \beta$ plasmid DNA demonstrated functional transgene expression in the $\beta$-galactosidase assay and ELISA. Therefore, this study provides, for the first time, strong indication that very long storage of plasmid DNA for 7 years does not limit its potential use for gene therapeutic applications, which represents a decisive factor for design and performance of clinical studies.

\section{Acknowledgments}

This work was supported by EMS Medical Systems, SA, Nyon, Switzerland, and by the J.W. \& J. Hector Foundation (M48.2), Weinheim, Germany. We would like to thank Margit Lemm and Lutz Menzel for excellent technical assistance.

\section{Author Disclosure Statement}

No competing financial interests exist.

\section{References}

Al-Dosari, M.S., and Gao, X. (2009). Nonviral gene delivery: principle, limitations, and recent progress. AAPS J. 11, 671681.

Anselmetti, D., et al. (1994). Biological materials studied with dynamic force microscopy. J. Vac. Sci. Technol. B 12, 15001503

Edelstein, M.L., et al. (2007). Gene therapy clinical trials worldwide to 2007-an update. J. Gene Med. 9, 833-842.

Escoffre, J.M., et al. (2012). New insight in the electrotransfer process: evidence for the involvement of the plasmid DNA topology. Curr. Gene Ther. 12, 417-422.

Fichtner, I., et al. (2004). Anticancer drug response and expression of molecular markers in early-passage xenotransplanted colon carcinomas. Eur. J. Cancer 40, 298-307. 
Gill, D.R., et al. (2009). Progress and prospects: the design and production of plasmid vectors. Gene Ther. 16, 165-171.

Ginn, S.L. et al. (2013). Gene therapy clinical trials worldwide to 2012 - an update. J. Gene Med. 15, 66-77.

Haase, R., et al. (2010). pEPito a significantly improved non-viral episomal expression vector for mammalian cells. BMC Biotechnol 10, 20.

Kim, B.I., et al. (2011). Long term structural changes of plasmid DNA studied by atomic force microscopy. Scanning 33, 405-412.

Lara, A.R., and Ramirez, O.T. (2012). Plasmid production for therapeutic applications. Methods Mol. Biol. 824, 271-303.

Lyubchenko, Y., et al. (1993). Atomic force microscopy of long DNA: imaging in air and under water. Proc. Natl. Acad. Sci. USA 90, 2137-2140.

Remaut, K., et al. (2006). Influence of plasmid DNA topology on the transfection properties of DOTAP/DOPE lipoplexes. J. Control. Release 115, 335-343.

Schleef, M., and Blaesen, M. (2009). Production of plasmid DNA as a pharmaceutical. Methods Mol. Biol. 542, 471-495.

Schleef, M., and Schmidt, T. (2004). Animal free production of ccc-supercoiled plasmids for research and clinical applications. J. Gene Med. 6, 45-53.

Schleef, M., et al. (2010). Production of non viral DNA vectors. Curr. Gene Ther. 10, 487-507.

Schmidt, T., et al. (1999). Quantitative analysis of plasmid forms by agarose and capillary gel electrophoresis. Anal. Biochem. 274, 235-240.

Tolmachov, O. (2009). Designing plasmid vectors. Methods Mol. Biol. 542, 117-129.

Voss, C. (2007). Production of plasmid DNA for pharmaceutical use. Biotechnol. Ann. Rev. 13, 201-222.
Voss, C., et al. (2003). Production of supercoiled multimeric plasmid DNA for biopharmaceutical application. J. Biotechnol. 105, 205-213.

Voss, C., et al. (2005). From bulk to delivery: plasmid manufacturing and storage. In DNA Pharmaceuticals. M. Schleef, ed. (Wiley-VCH, Weinheim, Germany), pp. 23-42.

Walther, W., et al. (2001). Non-viral in vivo gene delivery into tumors using a novel low volume jet-injection technology. Gene Ther. 8, 173-180.

Walther, W., et al. (2003). Stability analysis for long-term storage of naked DNA: impact on nonviral in vivo gene transfer. Anal. Biochem. 18, 230-235.

Walther, W., et al. (2008). Novel jet-injection technology for nonviral intratumoral gene transfer in patients with melanoma and breast cancer. Clin. Cancer Res. 14, 7545-7553.

Zheng, Y., et al. (2011). Identifying stabilizers of plasmid DNA for pharmaceutical use. J. Pharm. Sci. 100, 904-914.

Address correspondence to: Dr. Wolfgang Walther Max-Delbrück-Center for Molecular Medicine Robert-Rössle-Str. 10 13125 Berlin

Germany

E-mail: wowalt@mdc-berlin.de

Received for publication March 27, 2013;

accepted after revision September 25, 2013.

Published online: September 25, 2013. 